\title{
Study on Impact Behavior and Impact Force of Bridge Pier Subjected to Vehicle Collision
}

\author{
Deyuan Zhou, ${ }^{1}$ Ruiwen Li, ${ }^{1}$ Juan Wang, ${ }^{2}$ and Changtuan Guo \\ ${ }^{1}$ Research Institute of Structural Engineering and Disaster Reduction, Tongji University, Shanghai, China \\ ${ }^{2}$ South China Architectural Design \& Research Institute, Shanghai Branch, Shanghai, China \\ Correspondence should be addressed to Ruiwen Li; 1224river@tongji.edu.cn
}

Received 29 November 2016; Revised 16 April 2017; Accepted 9 May 2017; Published 16 July 2017

Academic Editor: Jeong-Hoi Koo

Copyright (c) 2017 Deyuan Zhou et al. This is an open access article distributed under the Creative Commons Attribution License, which permits unrestricted use, distribution, and reproduction in any medium, provided the original work is properly cited.

\begin{abstract}
The increasing occurrence of vehicle-pier collision accidents has significant influences on the safety of bridge structures. In order to study the impact behavior of bridge piers, a vehicle-double-pier collision numerical model was developed by LS-DYNA. Nonlinear material constitutive laws considering the strain-rate effect were used. The reliability of numerical analyses was validated. Parametric studies were carried out to investigate the effects of impact velocity, impact mass, and concrete and steel strength on the impact behaviors of piers and the impact forces. The relationship between failure modes of the impacted piers and impact energy was analyzed. Based on the numerical analysis results, the current impact design provisions of AASHTO, Eurocode, and JTG D60 were found to be unconservative, which could result in that piers designed with the current standard codes were vulnerable to the large impact energy. The recommended value of equivalent static force in the current standards is unreasonable.
\end{abstract}

\section{Introduction}

Studies on the crashworthiness of bridge piers have been increasingly reported, due to the increase of vehicle-pier collision accidents in the past years [1]. Some collision accidents resulted in the severe damage to the bridge structures, such as pier fracture and bridge collapse (in Figure $1[2]$ ), while others caused the slight damage to the piers, such as concrete cracking at the impact location (in Figure 2 [2]). To study behaviors and failure modes of the impact piers, it is necessary to accurately analyze the peak impact force, the maximum deformation, impact force, and deformation time histories of the impacted piers, which are also helpful to design protection schemes for piers against vehicle collision.

Full-size vehicle-pier collision tests were conducted by Buth et al. [3] using a 36.3-ton truck to impact at $80 \mathrm{~km} / \mathrm{h}$ a steel column with a diameter of $900 \mathrm{~mm}$. Based on the experimental data, $2669 \mathrm{kN}$ was suggested as the design impact force for vehicle collision. Fujikake et al. [4] carried out drop hammer impact tests on RC beams and the effect of reinforcement ratios on the dynamic response and damage levels of RC beams was analyzed. Saatci and Vecchio [5] conducted four groups of drop hammer impact tests on RC beams to study the effects of shear capacity on the impact behavior of RC beams and developed the simplified single degree of freedom methods for impact analysis of structures. In addition, Kishi et al. [6], Kulkarni and Shah [7], and Banthia et al. [8] also performed drop hammer impact tests on RC beams to study impact behaviors of RC beams without stirrups, fiber-reinforced concrete beam, and RC beam. It is clear that impact tests were mainly carried out to study the impact behavior and dynamic shear capacity of RC beams. Although several important results were obtained from these studies, they are difficult to be directly used for bridge piers. This is because the impact location and boundary condition between beams and piers are different. The impact location of beams is at the midspan, while the impact location of piers is at the bottom; beams seldom bear axial load, while piers always carry the weights from bridge superstructure and vehicles.

As physical impact tests are expensive, numerical models have been widely used to analyze the problems of vehiclepier collision. Chung et al. [9] carried out numerical models to assess the impact behavior of prefabricated piers under 


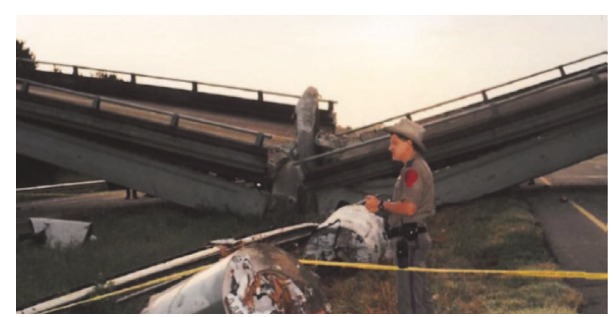

FIGURE 1: Bridge collapse [2].

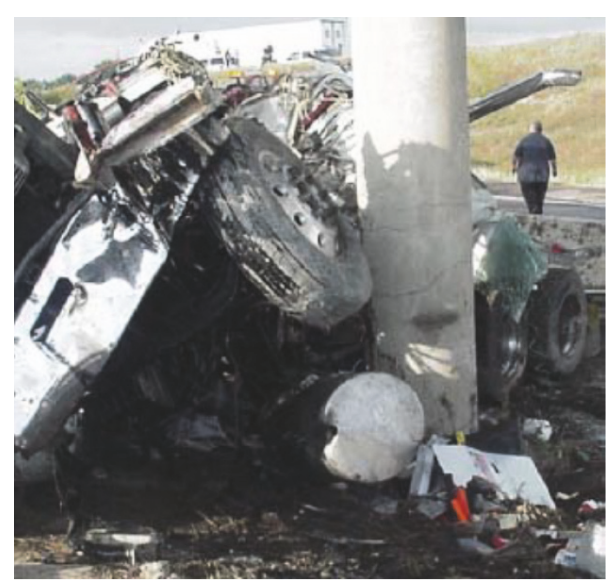

FIGURE 2: Concrete cracking [2].

vehicle collision by ABAQUS. EI-Tawil et al. [10] adopted LS-DYNA to simulate vehicle-pier collision and criticized AASHTO-LRFD [11] design impact force. Sharma et al. [12] performed the fragility estimates of RC piers subjected to vehicle collision with numerical analysis. Thilakarathna et al. [13] used LS-DYNA to conduct the vulnerability assessment on axially loaded concrete columns under impact loading. These studies made contribution to the parametric analysis, equations of the equivalent static force, and performance assessment of the single-pier under vehicle collision. However, double-piers are usually used as viaduct pier at present. Because different load-transferring mechanism, boundary condition, and distribution of kinetic energy absorption of the double-pier structural systems can be greatly affected by the impact behaviors of piers, the aforementioned study results are difficult to be directly used for the double-pier under impact loading. Additionally, the relationship between failure modes of the impacted piers and impact energy has not been studied, which is important for the establishment of collision-resistance design for piers.

This paper established a vehicle-double-pier collision numerical model by LS-DYNA, including the strain-rate effect on nonlinear material properties. The pier model was validated by comparing numerical impact force and deformation with the experimental data of the drop hammer impact test on RC beam. The reasonableness of the numerical model was validated by the failure pattern of the impacted pier with comparison between the real vehicle-pier collision accident and numerical results. Based on the validated numerical

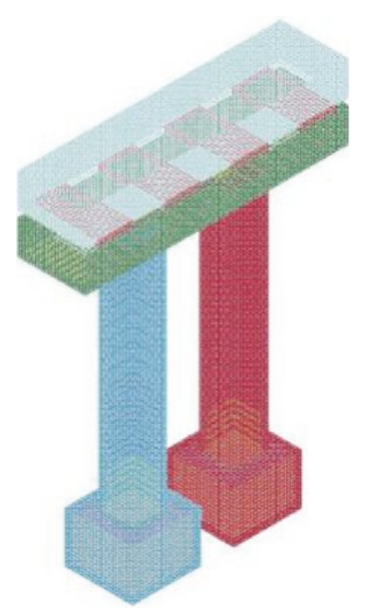

FIgURE 3: Numerical model of RC pier.

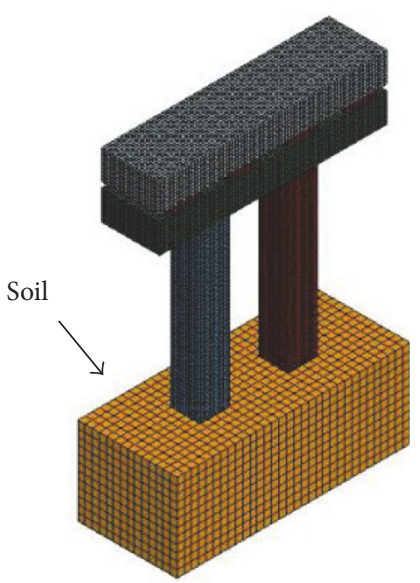

FIGURE 4: Numerical model of soil.

model, the effects of impact velocity and mass on the impact behavior of piers and the impact force were analyzed, and the effect of concrete and steel strength on the collision-resistance of piers was studied. The relationship between the failure mode of the impacted piers and impact energy was analyzed. Current impact design provisions of AASHTO-LRFD [14], Eurocode [15], and JTG D60 [16] use the equivalent static method to estimate the vehicle impact force. Therefore, this paper also discussed the reasonableness of the equivalent static force as the impact force for pier design.

\section{Numerical Model}

2.1. RC Pier Model. The prototype of bridge pier shown in Figures 3 and 4 was selected from a viaduct pier in Shanghai and design values are listed in Table 1 . Concrete and soil were modeled by solid elements. Steel was modeled by beam elements. The mesh size of each element is $50 \mathrm{~mm} \times 50 \mathrm{~mm}$.

Bond-slip effect in the interface between concrete and steel was applied by CONTACT_1D [19] in LS-DYNA. In CONTACT_1D, the slave nodes of beam elements are forced 
TABLE 1: Design values of RC pier.

\begin{tabular}{|c|c|c|c|c|c|}
\hline $\begin{array}{l}\text { Section } \\
\text { dimensions } / \mathrm{mm}^{2}\end{array}$ & Height/m & $\begin{array}{c}\text { Compressive } \\
\text { strength of } \\
\text { concrete/MPa }\end{array}$ & $\begin{array}{l}\text { Yield stress of } \\
\text { steel/MPa }\end{array}$ & Reinforcement/mm & Stirrup/mm \\
\hline $1200 \times 1500$ & 6.5 & 31.467 & 414 & $54 \mathrm{C} 32$ & C16@100/200 \\
\hline
\end{tabular}

TABLE 2: Corresponding information of MAT_CSCM_CONCRETE.

\begin{tabular}{lccccccccc}
\hline RO & NPLOT & INCER & IRATE & ERODE & RECOV & ITRETRC & PRED & FPC & DAGG \\
\hline $2.38 e-9$ & 1 & 0.000 & 1 & 1.050 & 0.000 & 0 & 0.000 & 31.65 & 20.000 \\
\hline
\end{tabular}

TABLE 3: Corresponding information of MAT_PLASTIC_KINEMATIC.

\begin{tabular}{lccccccccc}
\hline RO & E & NU & SIGY & ETAN & BETA & SRC & SRP & FS & VP \\
\hline $7.85 e-9$ & $2.1 e 6$ & 0.300 & 414.000 & $2.1 \times 10^{3}$ & 0.000 & 40.000 & 5.000 & 0.000 & 0 \\
\hline
\end{tabular}

TABLE 4: Corresponding parameters of MAT_SOIL_AND_FOAM [17].

\begin{tabular}{lccccccccc}
\hline RO & G & BULK & A0 & A1 & A2 & PC & VCR & REF & EPS1 \\
$1.63 e-9$ & 76.9 & $5.79 e 4$ & 0.0 & 0.0 & 0.467 & -0.0069 & 0.0 & 0.0 & 0.0 \\
\hline EPS2 & EPS3 & EPS4 & EPS5 & EPS6 & EPS7 & EPS8 & EPS9 & EPS10 & P1 \\
0.113 & 0.176 & 0.246 & 0.296 & 0.352 & 0.395 & 0.433 & 0.467 & 0.47 & 0.0 \\
\hline P2 & P3 & P4 & P5 & P6 & P7 & P8 & P9 & P10 & 650.65 \\
14.98 & 29.15 & 59.18 & 98.10 & 179.44 & 289.44 & 450.20 & 800.0 & \\
\hline
\end{tabular}

to slide along a master line of nodes embedded in the solid elements [20]. Fictitious springs are inserted between slave nodes and their projections over the master lines, which produce internal forces along the rebar and are proportional to the distance between slave nodes and master lines [20]. The bond shear modulus is $80 \mathrm{MPa} / \mathrm{mm}[20,21]$, the maximum allowable bond-slip is $0.3 \mathrm{~mm}[20,21]$, and the damage index is $0.12[20,21]$.

The material model MAT_CSCM_CONCRETE [22, 23] was used to simulate concrete mechanical properties; corresponding information was given in Table 2. This material model is smooth surface cap model and employed to model the dynamic behavior of concrete material under impact loading. The strain-rate effect is modeled with viscoplasticity.

The damage of concrete material under impact loading is also considered by damage index in MAT_CSCM_CONCRETE. The damage index is divided into tensile damage index $d_{t}$ and compressive damage index $d_{c}$.

$$
\begin{aligned}
& d_{t}=\frac{0.999}{D}\left[\frac{1+D}{1+D e^{-C\left(\tau_{t}-\tau_{0 t}\right)}}-1\right], \\
& d_{c}=\frac{d_{\max }}{B}\left[\frac{1+B}{1+B e^{-A\left(\tau_{c}-\tau_{0 c}\right)}}-1\right],
\end{aligned}
$$

where $\tau_{t}$ and $\tau_{c}$ are tensile energy and compressive energy for concrete material, respectively; $\tau_{0 t}$ and $\tau_{0 c}$ are tensile damage threshold and compressive damage threshold for concrete material, respectively; and $d_{\max }$ is the maximum damage index. The parameters $A$ and $B$ or $C$ and $D$ are used for setting the shape of the softening curve plotted as stressdisplacement or stress-strain.

The material model MAT_PLASTIC_KINEMATIC [19, 24] was used for modeling steel mechanical properties; corresponding information was given in Table 3. Von-Mises yield criterion is employed in MAT_PLASTIC_KINEMATIC. Moreover, this material model uses Cowper and Symonds model to take strain-rate effect on dynamic behaviors of steel material into account.

$$
\delta_{y}=\left[1+\left(\frac{\varepsilon}{C}\right)^{1 / p}\right]\left(\sigma_{0}+\beta E_{p} \varepsilon^{\mathrm{eff}}\right)
$$

where $\sigma_{0}$ is the initial yield stress; $\varepsilon^{\text {eff }}$ is the equivalent plastic strain; $E_{p}$ is the plastic hardening modulus; $\beta$ is hardening parameter; $\varepsilon$ is the strain rate. The parameters $C$ and $P$ are the constant.

The material model MAT_SOIL_AND_FOAM [19] was used for simulating soil properties. This material model should be used only in the situation when soils are confined within a structure or when geometric boundaries are present [19]. The constitutive parameters were given in Table 4 [17].

2.2. Truck Model. Truck model shown in Figure 5 is a Chinese truck model named Dongfeng, which is developed by FEA-MISEL Company [25]. This model was calibrated by the vehicle-rigid wall collision. It has the 11.88-m length, 2.46$\mathrm{m}$ width, 4.04-m height, and a total weight of 50 ton.

The material mode MAT_PIECEWISE_LINEAR_PLASTICITY [19] was used for modeling steel mechanical properties of the truck model. For this material model, an 
TABLE 5: Design values of beam specimen [18].

\begin{tabular}{lccccc}
\hline $\begin{array}{l}\text { Section } \\
\text { dimension } / \mathrm{mm}^{2}\end{array}$ & Span $/ \mathrm{m}$ & $\begin{array}{c}\text { Compressive } \\
\text { strength of } \\
\text { concrete/MPa }\end{array}$ & $\begin{array}{c}\text { Yield stress of } \\
\text { steel/MPa }\end{array}$ & Reinforcement $/ \mathrm{mm}$ & Stirrup/mm Axial load $/ \mathrm{kN}$ \\
\hline $300 \times 300$ & 4.0 & 47 & 523 & $4 \mathrm{C} 28$ & C12@150 \\
\hline
\end{tabular}

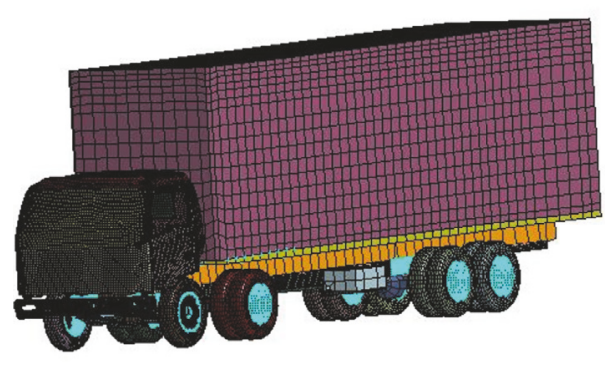

Figure 5: Numerical model of truck.

elastoplastic material with an arbitrary stress versus strain curve and arbitrary strain-rate dependency can be defined [19]. The detailed information about this material mode can be found from [19].

\subsection{Contact Type. CONTACT_AUTOMATIC_SURFACE_} TO_SURFACE (ASTS) was defined between truck and pier. In this contact type, the static friction coefficient is 0.3 [26]; the dynamic friction coefficient is 0.2 [26]; the exponential decay coefficient is 0.1 [27]; and the viscous damping coefficient is 30 [27]. The soft constraint penalty function was adopted for contact algorithm, because of the large difference in rigidity between truck and pier.

2.4. Model Validation. Validating the numerical model has different aspects like confirming the material models, contact types between different parts, failure modes of the impacted member, and hourglass control of numerical result. Three steps for model validation are described in this section. The first step is to validate the material models and contact types. The second and third steps are used to validate the failure mode and hourglass control, respectively.

2.4.1. Validation of Pier Model. Due to experimental conditions, it is hard to conduct vehicle-pier collision test to validate the corresponding numerical model. Therefore, in order to validate the reasonableness of pier model in LSDYNA, the numerical model was developed by authors to compare the midspan deformation and impact force time histories of the impacted beam with the published data of the drop hammer impact test on RC beam [18]. The experimental data of this drop hammer impact test has been used to validate other numerical models by Wijyewickrema [21, 28]. The RC beam specimen has a cross-sectional area of $300 \mathrm{~mm}$ $\times 300 \mathrm{~mm}$ and a span of $4000 \mathrm{~mm}$; other design values are listed in Table 5. The impact position is at the midspan of the

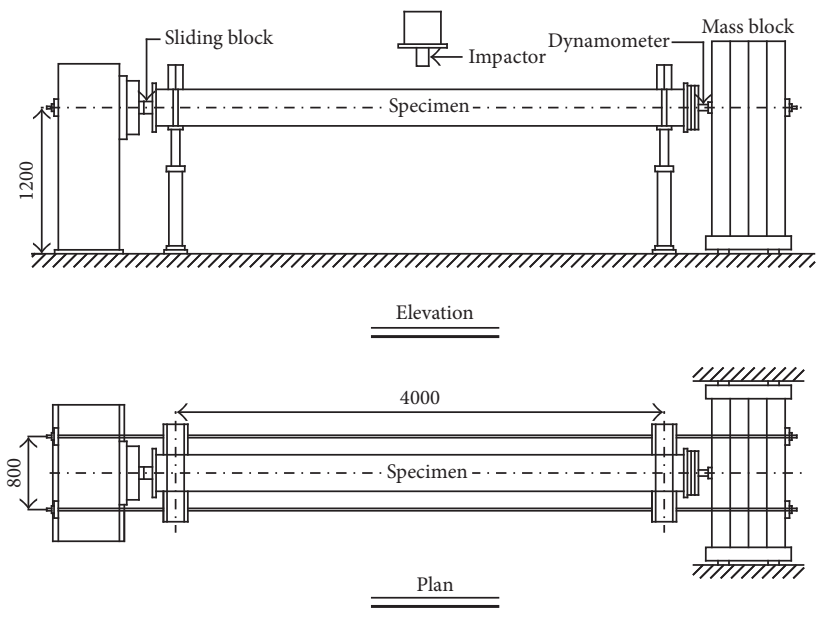

Figure 6: Drop hammer impact test [18].

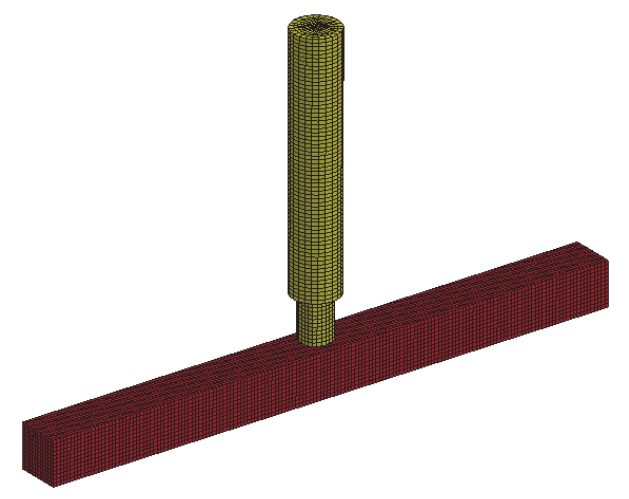

Figure 7: Numerical model of drop hammer impact test.

RC beam. A fixed boundary condition was applied at one end (in Figure 6) and a sliding boundary condition was used for the other end (in Figure 6). The impact force was applied by dropping a mass of $1140 \mathrm{~kg}$ at the midspan with the speed of $4.5 \mathrm{~m} / \mathrm{s}$.

The numerical model of impact test was developed in LS-DYAN, which is shown in Figure 7. Concrete and steel were modeled by MAT_CSCM_CONCRETE and MAT_PLASTIC_KINEMATIC, respectively. The contact type between drop hammer and beam was ASTS. Bond-slip effect was also considered.

Comparison of the midspan displacement between impact test and numerical results is shown in Figure 8. It can be found that the difference in the maximum displacement is insignificant. The maximum displacement of impact test is 
TABLE 6: Design values of bride pier [2].

\begin{tabular}{|c|c|c|c|c|c|}
\hline $\begin{array}{l}\text { Section } \\
\text { diameter/mm }\end{array}$ & Height $/ \mathrm{m}$ & $\begin{array}{c}\text { Compressive } \\
\text { strength of } \\
\text { concrete/MPa }\end{array}$ & $\begin{array}{l}\text { Yield stress of } \\
\text { steel/MPa }\end{array}$ & Reinforcement/mm & Stirrup/mm \\
\hline 762 & 4.0 & 28 & 414 & $11 C 28.65$ & C9.5@152 \\
\hline
\end{tabular}

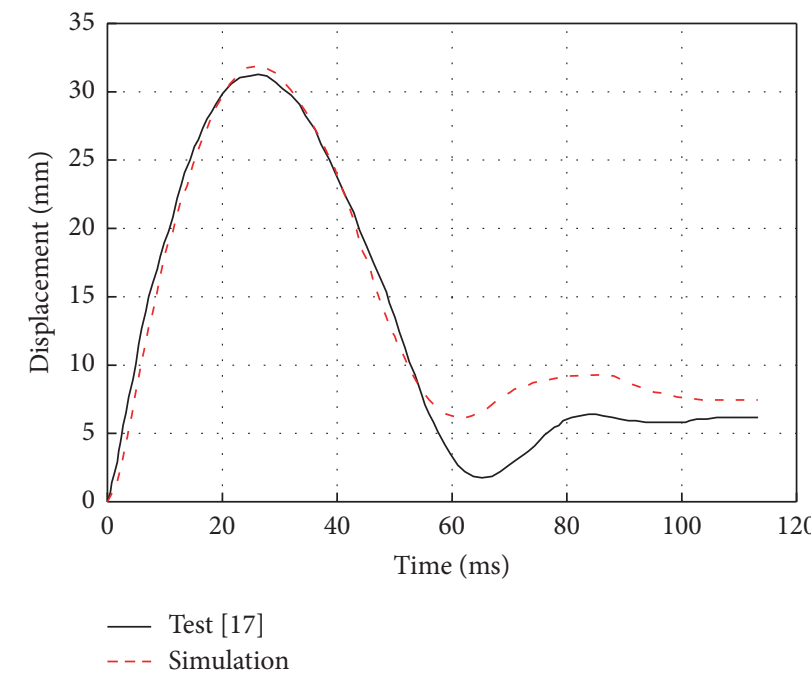

Figure 8: Comparison of midspan displacement between test and numerical result.

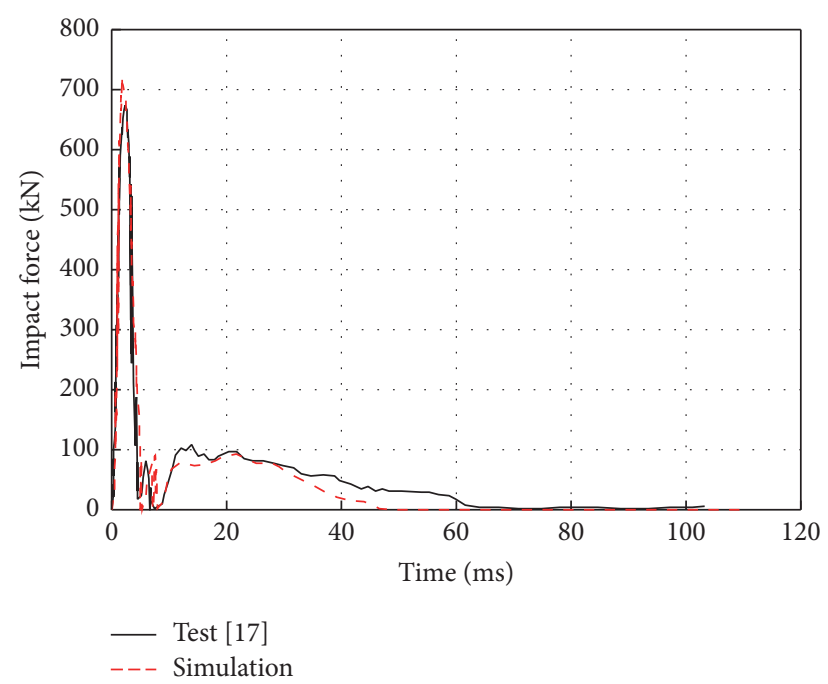

FIGURE 9: Comparison of impact force between test and numerical result.

$31.2 \mathrm{~mm}$, and the maximum displacement of numerical result is $31.7 \mathrm{~mm}$; the difference is $1.6 \%$. The residual displacement of numerical result is a little larger than the impact test. On the other hand, a good agreement of the impact force between impact test and numerical result was presented in Figure 9. The maximum impact force of impact test is $678 \mathrm{kN}$, and the maximum impact force of the numerical result is $721 \mathrm{kN}$; so the difference is $6.34 \%$. The attenuation trend of impact forces between impact test and numerical result is consistent.
Crack patterns of the impacted experimental specimen and concrete damage distribution of numerical result are shown in Figure 10. Cracks were observed to develop at the bottom of the impacted experimental specimen, and majority of concrete damage is concentrated at the same position of numerical model. These agreements of deformation, impact force, and crack pattern indicate that the material models (MAT_CSCM_CONCRETE and MAT_PLASTIC_KINEMATIC) and contact type (ASTS) of pier model have the capability of simulating the overall impact force and deformation behaviors of the pier.

2.4.2. Validation of Vehicle-Pier Collision Model. Based on the validated pier model, comparison of the failure mode of the impacted pier between the real vehicle-pier collision accident [2] and numerical simulation was developed by authors and the results were shown in Figures 11, 12, and 13. The detailed information of the pier was given in Table 6. The impact velocity of the truck is $80 \mathrm{~km} / \mathrm{h}$ and the mass is 36.92 ton.

As indicated in Figure 11, the pier suffered the shear failure, in which the concrete at the bottom of the pier fell off and the steel bars were exposed. It is clear from Figures 12 and 13 that the shear failure also occurred at the same position of the numerical model. The concrete elements were "broken" and the steel elements were also exposed. The failure mode of numerical model matches the reported failure mode.

2.4.3. Hourglass Control of Numerical Result. Figure 14 shows the time-history curves of various energies monitored in numerical model. It is clear that the total energy is basically conserved, indicating that the numerical model is reasonable. Moreover, hourglass energy is very low, less than $5 \%$. These results demonstrate that the numerical model is acceptable.

\section{Numerical Analyses and Parametric Studies}

Based on the validated numerical model, numerical analyses are carried out to study the effect of impact parameters on the impact forces and impact behaviors of piers. These include impact velocity, impact mass, and concrete and steel strength; the detailed information is given in Table 7. The process of vehicle-pier collision is shown in Figure 15, where impact velocity is $60 \mathrm{~km} / \mathrm{h}$ and impact mass is 40 ton.

3.1. Effect of Impact Velocity. Figure 16 shows the impact force time-history curves corresponding to different impact velocities. As it can be observed, the peak impact force increases as impact velocity increases. As impact velocity increases from $10 \mathrm{~km} / \mathrm{h}$ to $80 \mathrm{~km} / \mathrm{h}$, the peak impact force increases from $1662 \mathrm{kN}$ to $4710 \mathrm{kN}$. The main reason lies in impact energy. The larger impact velocity can result in higher 
TABLE 7: Vehicle impact cases.

\begin{tabular}{|c|c|c|c|c|c|c|c|c|c|c|c|c|c|c|}
\hline Parameter & \multicolumn{2}{|c|}{ PV-1 } & & \multicolumn{2}{|c|}{ PV-2 } & & \multicolumn{2}{|c|}{ PV-3 } & & \multicolumn{2}{|c|}{ PV-4 } & & \multicolumn{2}{|c|}{ PV-5 } \\
\hline Impact & $M$ & $V$ & & $M$ & $V$ & & $M$ & $V$ & & $M$ & $V$ & & $M$ & $V$ \\
\hline Velocity & 20 & 10 & & 20 & 20 & & 20 & 40 & & 20 & 60 & & 20 & 80 \\
\hline Parameter & \multicolumn{2}{|c|}{ PM-1 } & & \multicolumn{2}{|c|}{ PM-2 } & & \multicolumn{2}{|c|}{ PM-3 } & & \multicolumn{2}{|c|}{ PM-4 } & & \multicolumn{2}{|c|}{ PM-5 } \\
\hline Impact & $M$ & $V$ & & $M$ & $V$ & & $M$ & $V$ & & $M$ & $V$ & & $M$ & $V$ \\
\hline Mass & 10 & 60 & & 20 & 60 & & 30 & 60 & & 40 & 60 & & 50 & 60 \\
\hline Parameter & & PC-1 & & & PC-2 & & & PC-3 & & & PC-4 & & & \\
\hline Concrete & $M$ & $V$ & $C$ & $M$ & $V$ & $C$ & $M$ & $V$ & $C$ & $M$ & $V$ & $C$ & & \\
\hline Strength & 40 & 60 & 27 & 40 & 60 & 31 & 40 & 60 & 35 & 40 & 60 & 39 & & \\
\hline Parameter & & PS-1 & & & PS-2 & & & PS-3 & & & & & & \\
\hline Steel & $M$ & $V$ & $S$ & $M$ & $V$ & $S$ & $M$ & $V$ & $S$ & & & & & \\
\hline Strength & 40 & 60 & 335 & 40 & 60 & 400 & 40 & 60 & 500 & & & & & \\
\hline
\end{tabular}

Note: $M$ is mass, and its unit is ton; $V$ is velocity, and its unit is $\mathrm{km} / \mathrm{h} ; C$ is concrete strength, and its unit is $\mathrm{MPa}$; $S$ is steel strength, and its unit is $M P a$.

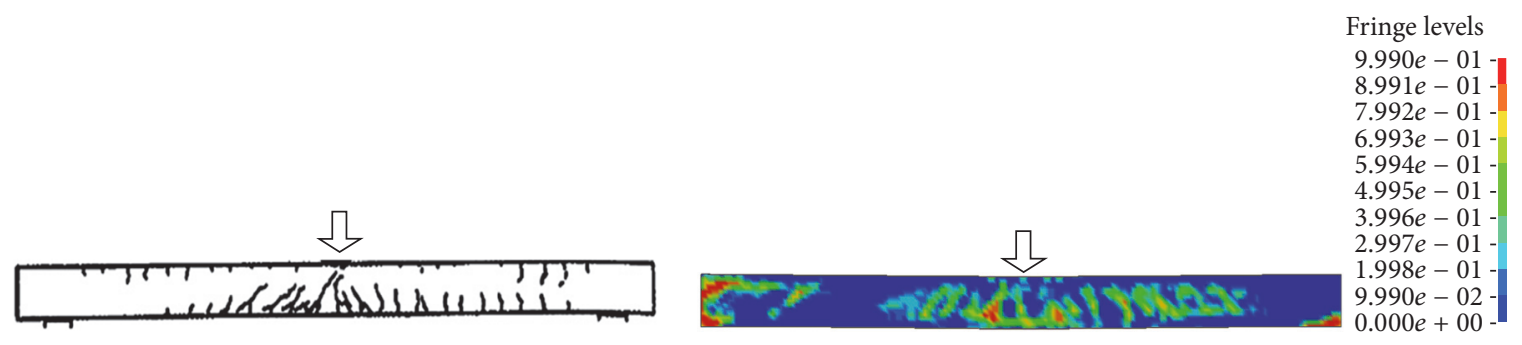

(a) Impact test result [18]

(b) Numerical result

FIGURE 10: Crack propagation in the impact test and the numerical result.

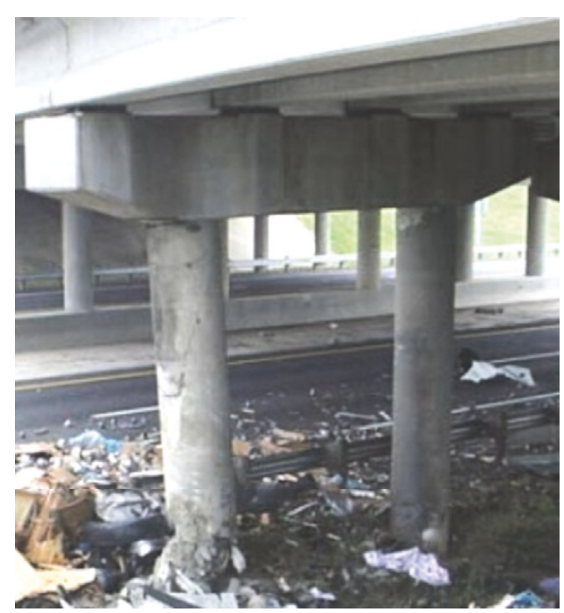

FIGURE 11: Failure mode of the pier of [2].

impact energy, causing a larger peak impact force. It can be seen from Figure 16 that impact velocity also affects the impact duration. A larger impact velocity leads to relatively longer impact duration because of the larger vehicle and pier deformation due to absorbing the higher impact energy.

Figure 17 shows the displacement time-history curves for different impact velocities (the measured position is at

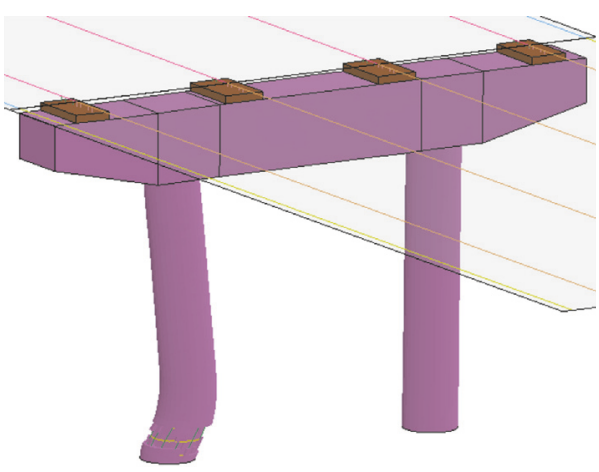

FIGURE 12: Failure mode of the pier of numerical model.

the impact location). As shown, the displacement increases with the increase of impact velocity. As impact velocity increases from $10 \mathrm{~km} / \mathrm{h}$ to $40 \mathrm{~km} / \mathrm{h}$, the maximum displacement increases from only $5 \mathrm{~mm}$ to $20 \mathrm{~mm}$. This is because the local damage and bend-shear failure occurred as impact velocities are within the range of $10 \mathrm{~km} / \mathrm{h}$ to $40 \mathrm{~km} / \mathrm{h}$. On these failure modes, the impact energy is relatively small compared with the pier resistance; as a consequence, displacements are relatively small. As impact velocity exceeds $60 \mathrm{~km} / \mathrm{h}$, the maximum displacement increases dramatically, due to the large impact energy causing the shear failure and 


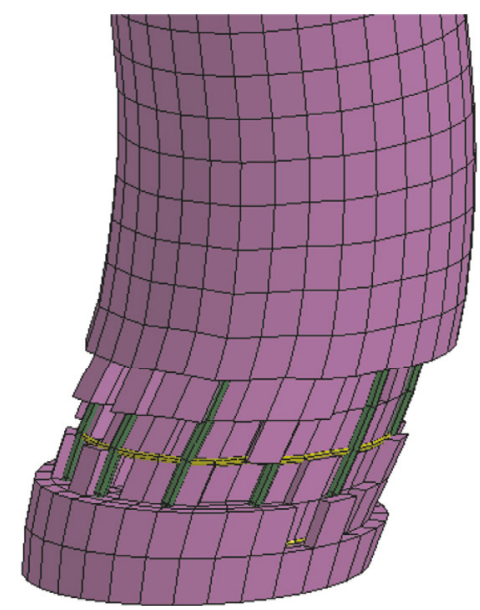

FIGURE 13: Failure mode of the pier of numerical model.

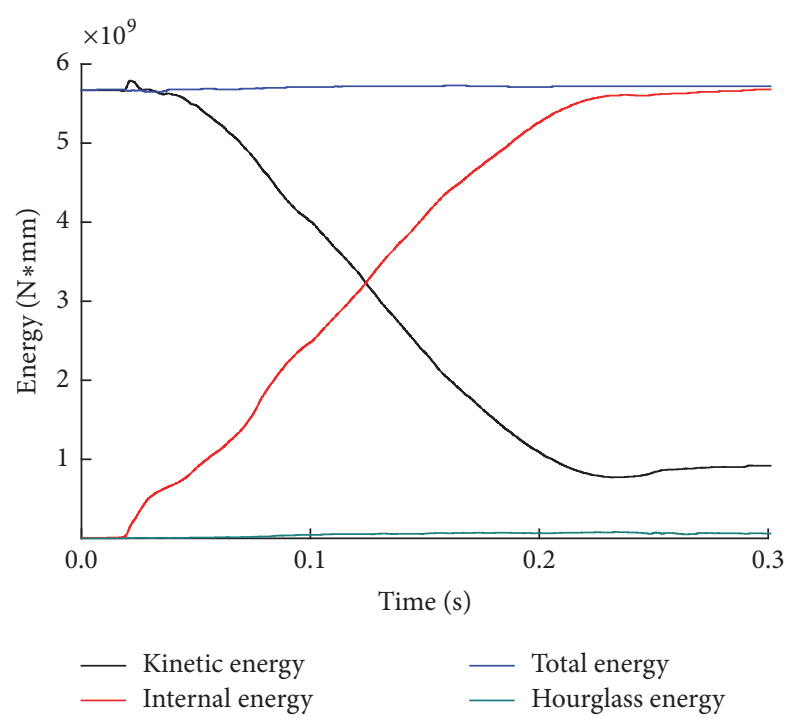

FIGURE 14: Development of various energies.

severe damage to concrete, which can make the pier stiffness decrease resulting in much large displacement.

3.2. Effect of Impact Mass. Figures 18 and 19 show the impact force and displacement time-history curves, corresponding to different impact masses. In Figure 18, the impact force was found to have proportional relationship with impact mass. When impact mass is 10 ton and 50 ton, the peak impact force is $2818 \mathrm{kN}$ and $7790 \mathrm{kN}$, respectively. This is because greater impact mass causes higher impact energy, resulting in larger peak impact force.

The displacement time-history curves shown in Figure 19 demonstrate that the maximum displacement increases as impact mass increases. When impact mass is less than 30 ton, the failure mode appears with local damage, causing a smaller displacement. When impact mass increases to 40 ton, the obvious bending deformation occurs, which prolongs the impact process and displacement. When impact mass exceeds 40 ton, the maximum displacement is more than $300 \mathrm{~mm}$. This is because the failure mode is dominated by shear failure, and the pier is broken completely. Most concrete elements are eroded and the shear capacity of the impacted piers decreases, leading to much larger plastic deformation in the collision process.

3.3. Effect of Concrete Strength. Figure 20 shows the impact force time-history curves of different concrete strengths. It can be seen that the peak impact force and the impact duration are independent of concrete strength. All impacted piers suffer shear failure. The peak impact forces are about $5800 \mathrm{kN}$ and the impact durations are approximately $250 \mathrm{~ms}$. This is because the concrete is brittle material and it is difficult for the brittle material to perform the high shear capacity in the short impact duration, although the concrete strength is relatively high.

Figure 21 shows the different displacement time-history curves. As shown, all the maximum displacement is about $160 \mathrm{~mm}$, which indicates that the collision-resistance of piers is almost insensitive to concrete strength. This is because the deformation is mainly controlled by impact energy and pier stiffness, while the pier stiffness is almost not affected by concrete strength. As a result, the concrete strength has little influence on the maximum displacement and residual displacement, when the impact energy and geometric dimensions of piers keep constant.

3.4. Effect of Steel Strength. The impact force time-history curves corresponding to different steel strengths were plotted in Figure 22. All failure modes of the impacted piers are shear failure. The observation indicates that the impact duration is relatively independent of the steel strength while the peak impact force depends on it. The peak impact force is $5533 \mathrm{kN}$, $5816 \mathrm{kN}$, and $6175 \mathrm{kN}$, for steel strength of HRB335, HRB400, and HRB500, respectively. The impact duration is about $250 \mathrm{~ms}$. The shear capacity of piers increased as the steel strength is improved. Therefore, the pier with higher steel strength can resist the larger impact energy, resulting in a larger impact force.

Different displacement time-history curves in Figure 23 show that the maximum displacement decreases as steel strength increases, which indicates that the collisionresistance of piers is improved with a higher steel strength. When the steel strength is HRB335, the maximum displacement is $188 \mathrm{~mm}$. The maximum displacement decreases to $162 \mathrm{~mm}$ and $136 \mathrm{~mm}$, for steel of HRB400 and HRB500, respectively. This is because the shear capacity and residual stiffness of the pier are improved with higher steel strength, which leads to the smaller maximum displacement and residual displacement.

\section{Discussion}

4.1. Impact Parameters. According to the numerical results of impact forces and displacements, the impact parameters can be divided into two categories. 

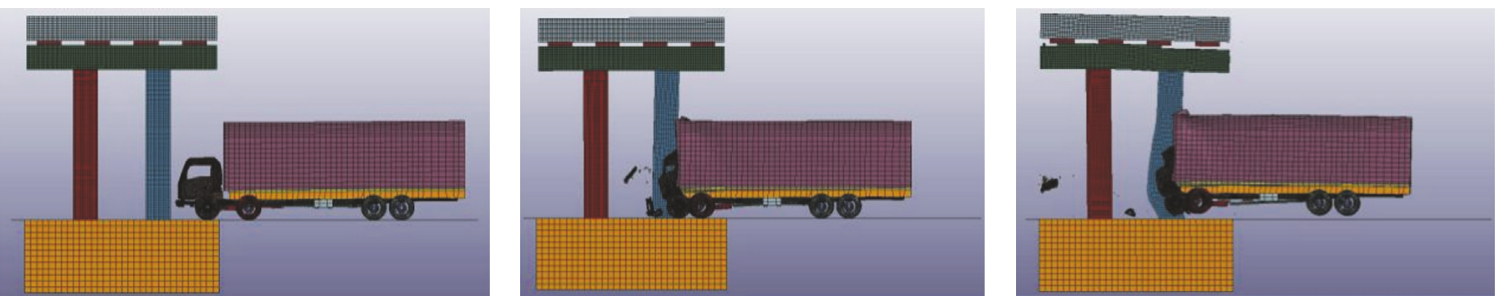

Figure 15: Process of vehicle-pier collision.

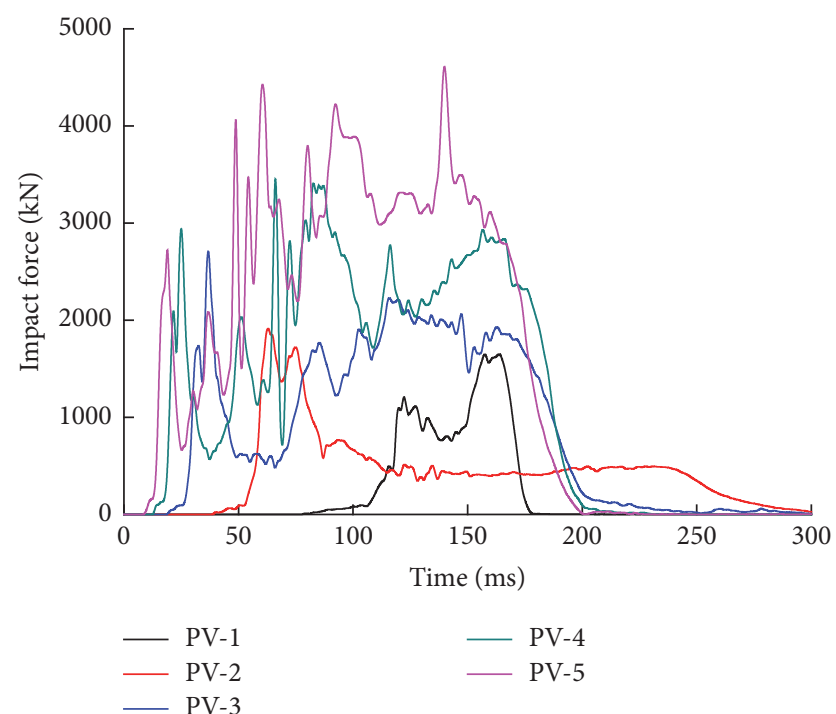

FIGURE 16: Impact force time-history curves under different impact velocities.

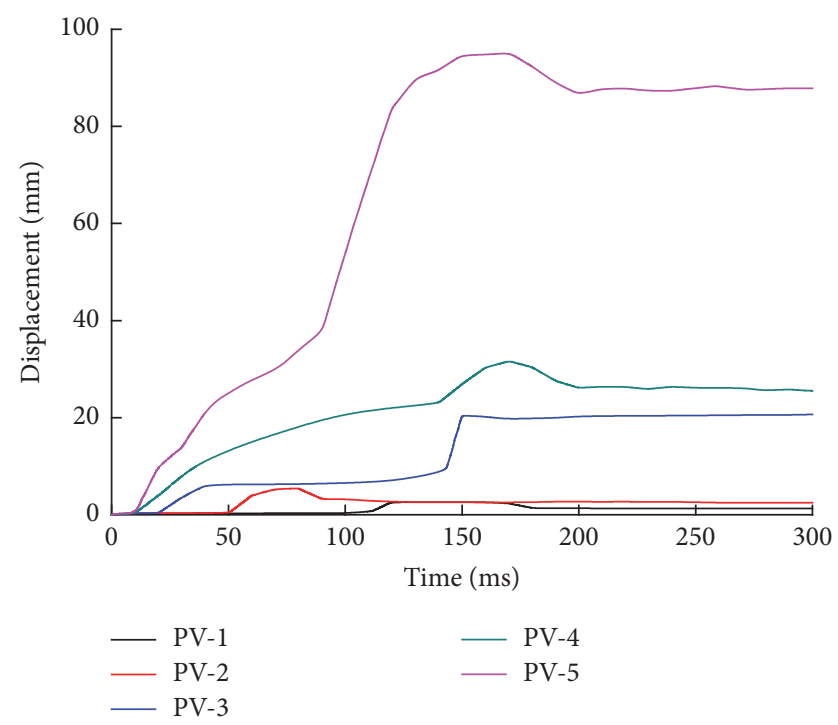

FIGURE 17: Displacement time-history curves under different impact velocities.

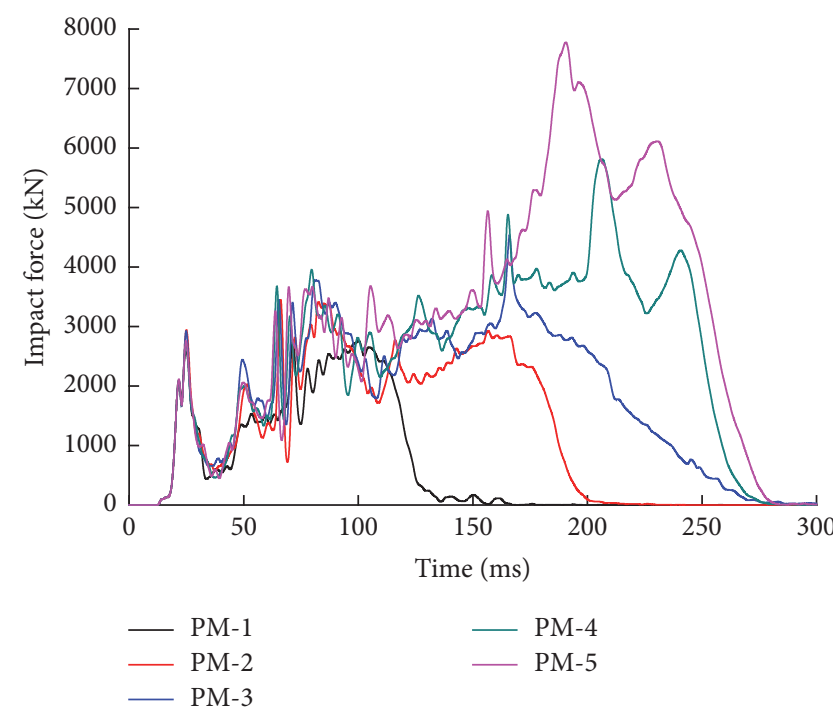

FIGURE 18: Impact force time-history curves under different impact masses.

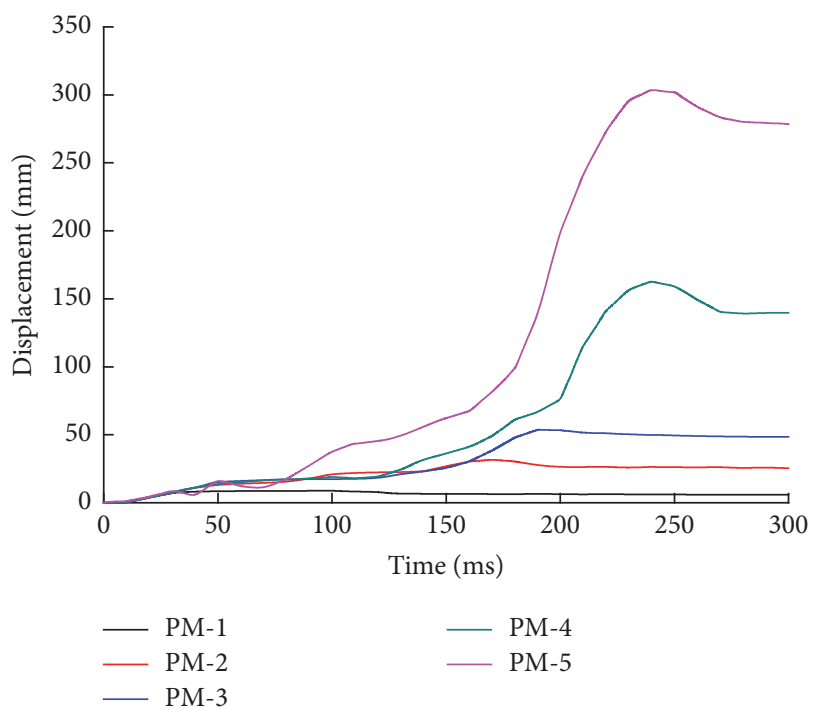

FIGURE 19: Displacement time-history curves under different impact masses. 


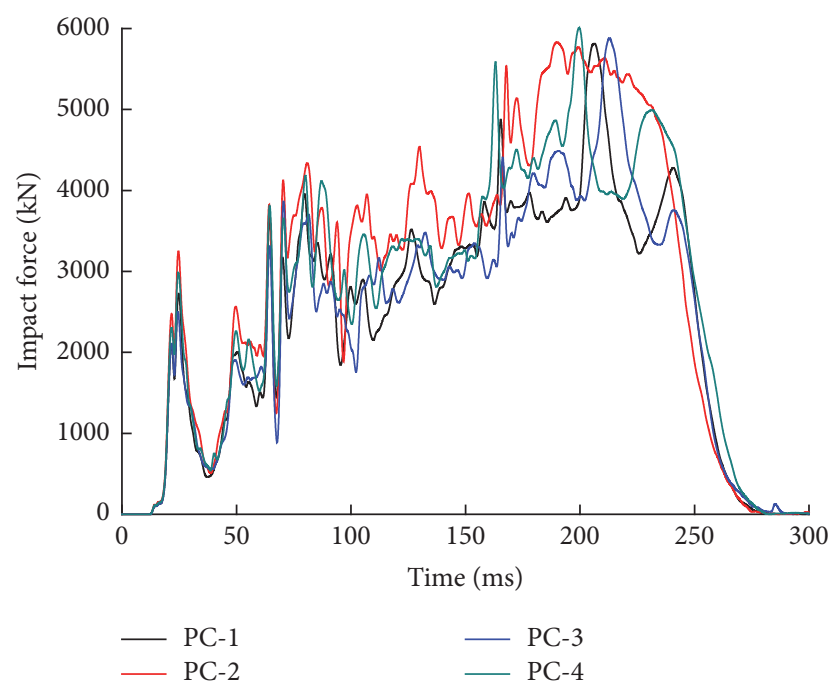

FIGURE 20: Impact force time-history curves under different concrete strengths.

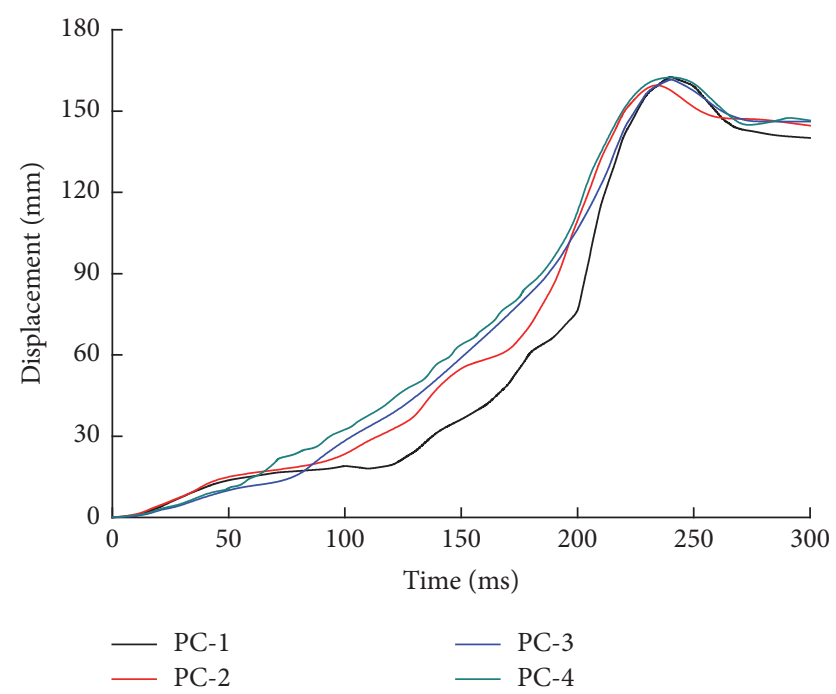

FIGURE 21: Displacement time-history curves under different concrete strengths.

4.1.1. Vehicle Parameters. Impact velocity, impact mass, and impact energy are parameters associated with vehicle, which have great influences on the impact force and deformation of the impacted piers. The influence of impact energy is the most significant. It can be drawn that the peak impact force and the maximum deformation increase as the impact energy increases.

4.1.2. Pier Parameters. Concrete and steel strength are parameters related to piers, which affect the collisionresistance of the piers. The impact force, impact duration, and deformation are insensitive to concrete strength, while the deformation is greatly affected by steel strength. The collisionresistance of piers is improved with higher steel strength, which can resist the large deformation in the impact location

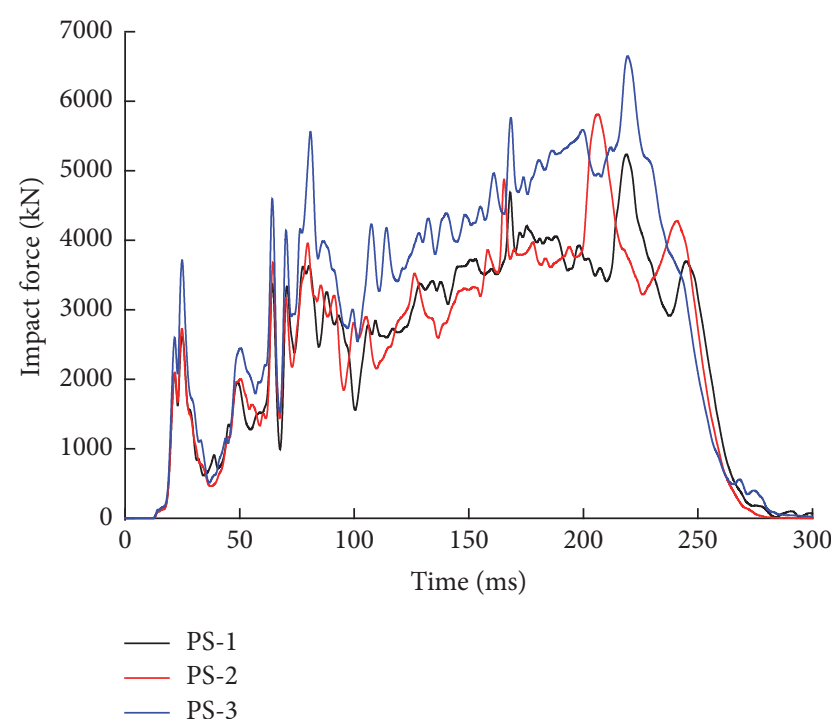

FIGURE 22: Impact force time-history curves under different steel strengths.

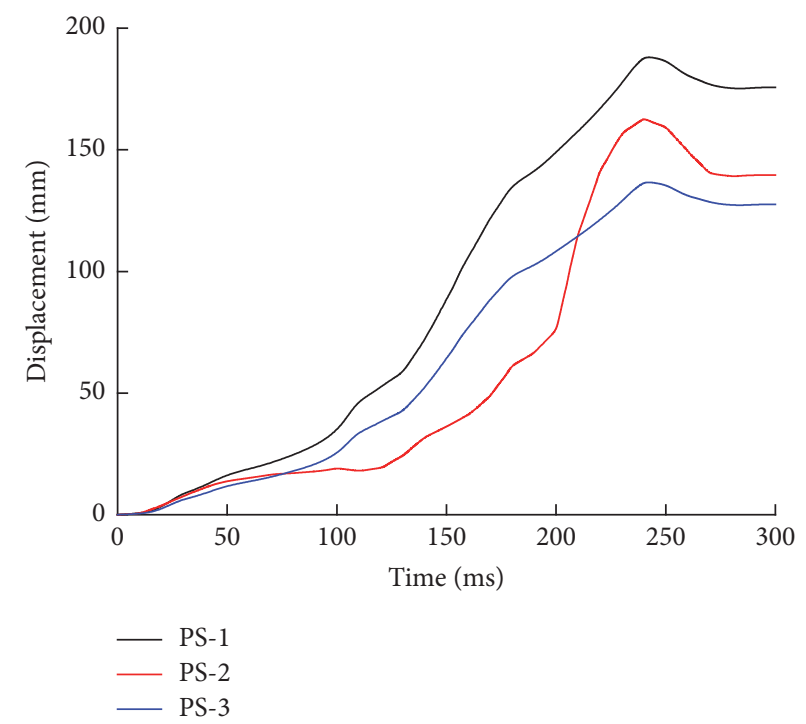

FIGURE 23: Displacement time-history curves under different steel strengths.

and result in the higher pier residual stiffness to withstand the greater impact force.

4.2. Performance Level of the Impacted Piers. In performancebased analysis, the performance levels are defined according to different failure modes of numerical results, which are helpful to design piers against vehicle collision. Table 8 lists the detailed failure description and performance description for each performance level. Piers with local damage can be continuously used. If piers suffer the bend-shear failure after vehicle collision, they need to be repaired even though the possibility of bridge collapse may be low. Piers with shear failure must be replaced since this failure mode has a higher probability of bridge collapse. 
TABLE 8: Performance level of the impacted piers.

\begin{tabular}{lccc}
\hline $\begin{array}{l}\text { Performance } \\
\text { level }\end{array}$ & Failure mode & Failure description & Performance description \\
\hline P1 & Local damage & $\begin{array}{c}\text { Microcracks occur at impact location without any } \\
\text { obvious deformation. }\end{array}$ & $\begin{array}{c}\text { Operational pier without any } \\
\text { obvious damage }\end{array}$ \\
P2 & $\begin{array}{c}\text { Bend-shear } \\
\text { failure }\end{array}$ & $\begin{array}{c}\text { Minor of concrete cover fell off and some of } \\
\text { reinforcement yielded with small deformation. }\end{array}$ & Operational pier with repair \\
P3 & Shear failure & $\begin{array}{c}\text { Significant cracks occur and stirrup is exposed } \\
\text { and fractured with large deformation. }\end{array}$ & Pier fracture \\
\hline
\end{tabular}

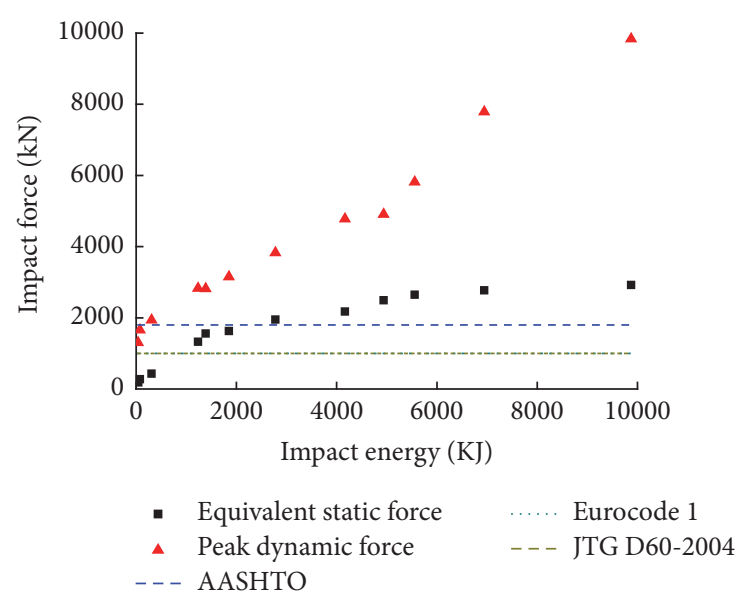

FIgURE 24: Comparison among the design impact force, the peak impact force, and the equivalent static force.

4.3. Current Impact Design Provisions Discussion. In order to evaluate the reasonableness of the equivalent static force as impact design force of AASHTO-LRFD, Eurocode 1, and JTG D60-2004, the peak impact force (PIF) from numerical results was converted into the equivalent static force (ESF), according to the equivalent displacement method; that is,

$$
\mathrm{ESF}=\frac{\int_{0}^{t} p(i) d(i) d i}{d_{\max }}
$$

where $p(i)$ is the instantaneous impact force, $t$ is the impact duration, $d(i)$ is the instantaneous deformation, $d_{\max }$ is the maximum deformation, and $i$ is the instantaneous moment.

The results are shown in Figure 24. As indicated, the ESF is larger than the Eurocode 1 and JTG D60-2004 impact design force $(1000 \mathrm{kN})$, as the impact velocity is $40 \mathrm{~km} / \mathrm{h}$ and impact mass is 20 ton. The ESF is larger than the AASHTOLRFD impact design force $(1800 \mathrm{kN})$, when the impact velocity is $60 \mathrm{~km} / \mathrm{h}$ and impact mass is 30 ton. As impact velocity increases to $80 \mathrm{~km} / \mathrm{s}$ and impact mass reaches 40 ton, the ESF is 1.9 times larger than Eurocode 1 and JTG D602004 impact design force and 1.6 times larger than AASHTOLRFD impact design force. It demonstrates that the impact design forces in current standards are unconservative. It also can be found that the PIF is 3.5 times the ESF averagely, meaning that the pier designed with the present safety factor (1.5) could hardly resist heavy vehicle collision.
Using ACI-318 [29], Eurocode 2 [30], and GB 50010-2010 [31], the shear capacity of a pier designed with the static method is larger than ESP. This implies that it is almost impossible that vehicle collision can cause shear failure to the pier. However, numerical results indicate that the main failure mode is shear failure, which indicates that the recommended value of equivalent static force in the current standards is unreasonable. It is possible that the severe shear failure and collapse could occur in the pier that is designed with the current standard codes, if the impact energy increases to a high extent.

\section{Conclusions}

In this study, the vehicle-pier collision numerical model was developed in LS-DYNA and validated. Nonlinear material constitutive laws considering strain-rate effect were used. Based on the validated numerical model, parametric studies were carried out to investigate the effect of impact velocity, impact mass, and concrete and steel strength on the impact behaviors of the impact piers and the impact forces. The relationship between failure modes of the impacted piers and impact energy was analyzed. Main conclusions were summarized as follows:

(1) The deformation of the impacted piers and the impact force are mainly governed by impact energy. The maximum deformation and the peak impact force increase as the impact energy increases.

(2) The impact force, impact duration, and deformation are not sensitive to concrete strength, while the deformation is greatly affected by steel strength. The collision-resistance of piers is improved with higher steel strength, which can resist large deformation at the impact location and result in the higher pier residual stiffness to withstand the greater impact force.

(3) The performance levels of the impacted piers can be divided into three categories according to different failure modes. Performance level P1 is assigned to the case that local damage takes place at the impact location without any obvious deformation, as the impact energy is much smaller than the pier resistance. Performance level P2 is assigned to the scenario that pier suffers the bend-shear failure with the relatively large deformation as the impact energy 
is little smaller than the pier resistance. Performance level P3 is assigned to the case that the impacted pier is fractured with the shear failure when the impact energy is greater than the pier resistance.

(4) Study results and failure modes of impacted piers demonstrate that the current impact design provisions of AASHTO, Eurocode, and JTG D60 could be unconservative. Piers designed with present provisions might be vulnerable to large impact energy. Recommended equivalent static force values in current standards are unreasonable.

\section{Conflicts of Interest}

The authors declare that there are no conflicts of interest regarding the publication of this paper.

\section{Acknowledgments}

The authors are grateful for financial support from National Natural Science Foundation of China (Grant no. 51438010). Supports from Professor Jiang Qian of Tongji University are appreciated. Supports from Texas A\&M Transportation Institute are also acknowledged.

\section{References}

[1] L. Xu, X. Lu, H. Guan, and Y. Zhang, "Finite-element and simplified models for collision simulation between overheight trucks and bridge superstructures," Journal of Bridge Engineering, vol. 18, no. 18, pp. 1140-1151, 2013.

[2] C. E. Buth, W. F. Williams, M. S. Brackin et al., "Analysis of large truck collisions with bridge piers: phase 1," Report of guidelines for designing bridge piers and abutments for vehicles collisions, Texas Transportation Institute, Texas A \& M University, TX, USA, 2010.

[3] C. E. Buth, M. S. Brackin, W. F. Willams et al., "Collision loads on bridge piers: phase 2," Report of guidelines for designing bridge piers and abutments for vehicle collisions, Texas Transportation Institute, Austin, TX, USA, 2011.

[4] K. Fujikake, B. Li, and S. Soeun, "Impact response of reinforced concrete beam and its analytical evaluation," Journal of Structural Engineering, vol. 135, no. 8, pp. 938-950, 2009.

[5] S. Saatci and F. J. Vecchio, "Effects of shear mechanisms on impact behavior of reinforced concrete beams," ACI Structural Journal, vol. 106, no. 1, pp. 78-86, 2009.

[6] N. Kishi, H. Mikami, K. G. Matsuoka, and T. Ando, "Impact behavior of shear-failure-type RC beams without shear rebar," International Journal of Impact Engineering, vol. 27, no. 9, pp. 955-968, 2002.

[7] S. M. Kulkarni and S. P. Shah, "Response of reinforced concrete beams at high strain rates," ACI Structural Journal, vol. 95, no. 6, pp. 705-715, 1998.

[8] N. Banthia, S. Mindess, A. Bentur, and M. Pigeon, "Impact testing of concrete using a drop-weight impact machine," Experimental Mechanics, vol. 29, no. 1, pp. 63-69, 1989.

[9] C. H. Chung, J. Lee, and J. H. Gil, "Structural performance evaluation of a precast prefabricated bridge column under vehicle impact loading," Structure and Infrastructure Engineering, vol. 10, no. 6, pp. 777-791, 2014.
[10] S. El-Tawil, E. Severino, and P. Fonseca, "Vehicle collision with bridge piers," Journal of Bridge Engineering, vol. 10, no. 3, pp. 345-353, 2005.

[11] American Association of State Highway and Transportation Officials Load and Resistance Factor, AASHTO LRFD Bridge Design Specifications, AASHTO, Wash, USA, 2nd edition, 1998.

[12] H. Sharma, P. Gardoni, and S. Hurlebaus, "Probabilistic demand model and performance-based fragility estimates for RC column subject to vehicle collision," Engineering Structures, vol. 74, pp. 86-95, 2014.

[13] H. M. I. Thilakarathna, D. P. Thambiratnam, M. Dhanasekar, and N. Perera, "Numerical simulation of axially loaded concrete columns under transverse impact and vulnerability assessment," International Journal of Impact Engineering, vol. 37, no. 11, pp. 1100-1112, 2010.

[14] American Association of State Highway and Transportation Officials, AASHTO-LRFD Bridge Design Specifications, customary US units, Wash, DC, USA, 6th edition, 2012.

[15] Eurocode 1: actions on structures-Part 1-7: general actionsaccidental actions. BS EN 1991-1-7: 2006, European Committee for Standardization, 2010.

[16] "General code for design of highway bridges and culverts," Tech. Rep. JTG D60-2004, Beijing, 2004.

[17] L. Schwer, "Calibrating the soil \& foam model to norwegian sandy soil," Geomaterial Modeling, 2010.

[18] M. Feyerabend, Hard transverse impacts on steel beams and reinforced concrete beams [Ph.D. thesis], University of Karlsruhe, Germany, 1988.

[19] LS-DYNA, LS-DYNA Keyword User's Manual, Livermore Software Technology Corporation, Livermore, Calif, USA, 2010.

[20] Y. C. Shi, Z. X. Li, and H. Hao, "Bond slip modelling and its effect on numerical analysis of blast-induced responses of RC columns," Structural Engineering and Mechanics, vol. 32, no. 2, pp. 251-267, 2009.

[21] M. A. K. M. Madurapperuma and A. C. Wijeyewickrema, "Performance of reinforced concrete columns impacted by waterborne shipping containers," Advances in Structural Engineering, vol. 15, no. 8, pp. 1307-1327, 2012.

[22] Y. D. Murray, A. Abu-Odeh, and R. Bligh, "Evaluation of LSDYNA concrete material model 159," Tech. Rep. FHWA-HRT05-063, 2007.

[23] Y. D. Murray, “User's manual for LS-DYNA concrete material model 159," Tech. Rep. FHWA-HRT-05-062, 2007.

[24] J. O. Hallquist, LS-DYNA Keywords User'S Manual, Livermore Software Technology Corporation, Calif, USA, 2012.

[25] http://www.misesl.com.

[26] L. Bu, Simplified Dynamical Probability Method for Ship-Bridge Collision. Master dissertation [Master, thesis], Tongji University, China, 2011.

[27] W. Juan, The crashworthiness of the substructures of urban bridges impacted by heavy vehicles [Ph.D. thesis], Tongji University, China, 2015.

[28] M. A. K. M. Madurapperuma and A. C. Wijeyewickrema, "Response of reinforced concrete columns impacted by tsunami dispersed 20' and 40' shipping containers," Engineering Structures, vol. 56, pp. 1631-1644, 2013.

[29] American Concrete Institute (ACI), Building Code Requirements for Structural Concrete (318-05) And Commentary (318R05), ACI, Farmingtion Hills, Mich, USA. 
[30] Eurocode 2: Design of concrete structures - Part 1-1: General rules and rules for buildings. BS EN 1992-1-1:2006, European Committee for Standardization, 2004.

[31] GB 50010-2010. Code for design of concrete structures. Beijing, 2010. 


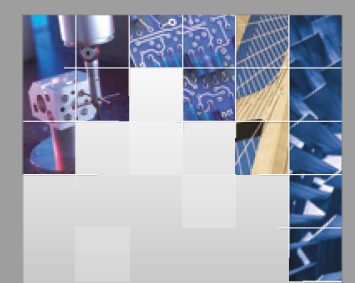

\section{Enfincering}
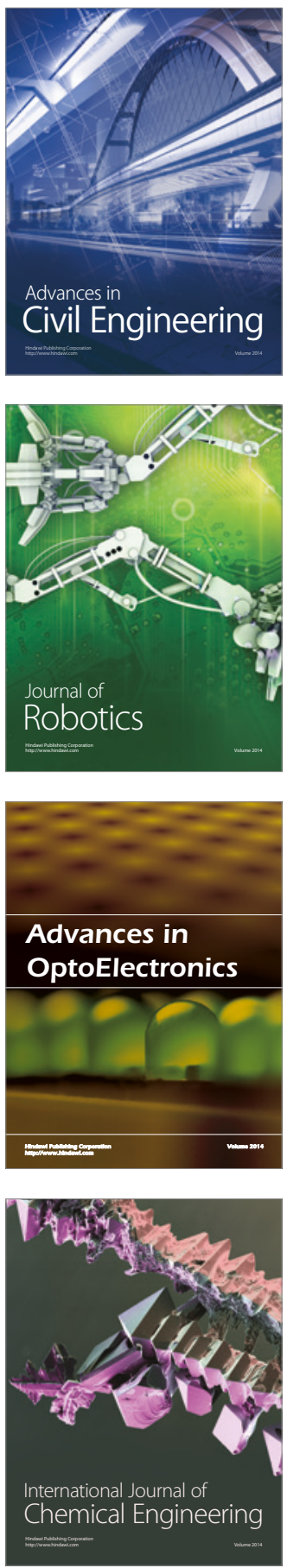

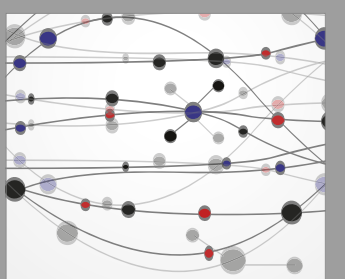

The Scientific World Journal

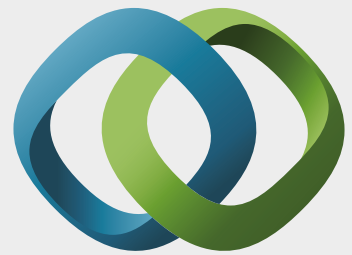

\section{Hindawi}

Submit your manuscripts at

https://www.hindawi.com
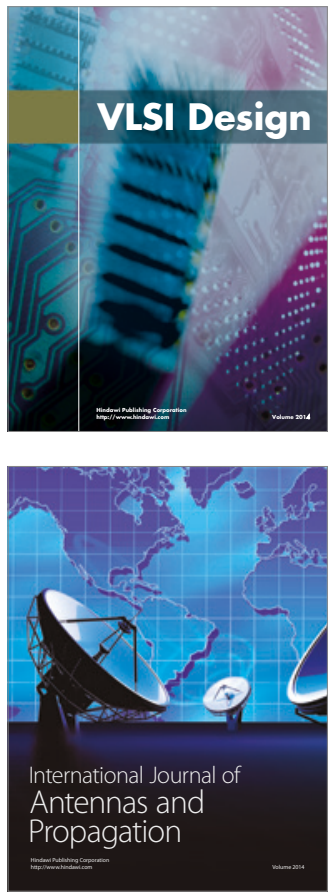

\section{Rotating}

Machinery
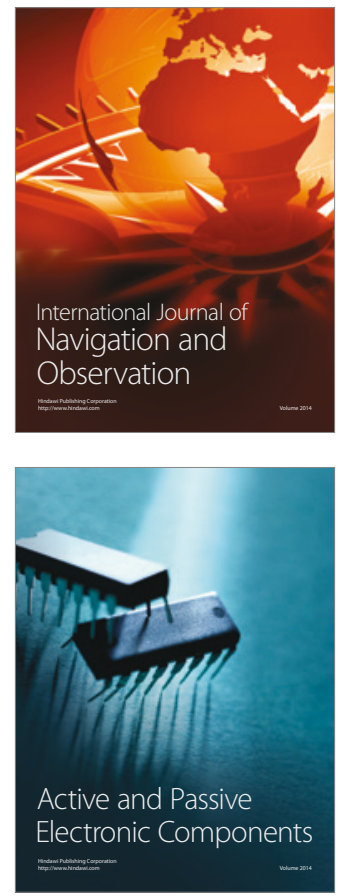
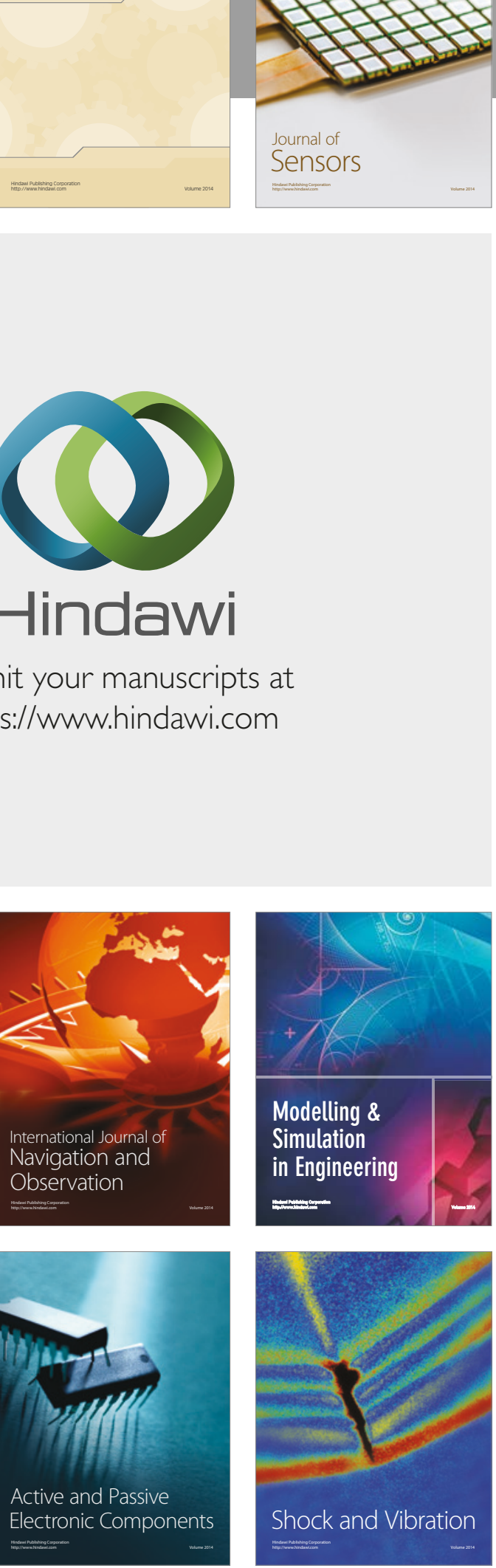
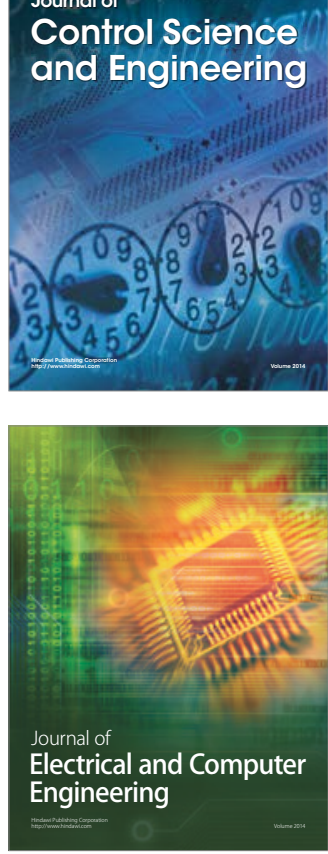

Distributed

Journal of

Control Science

and Engineering
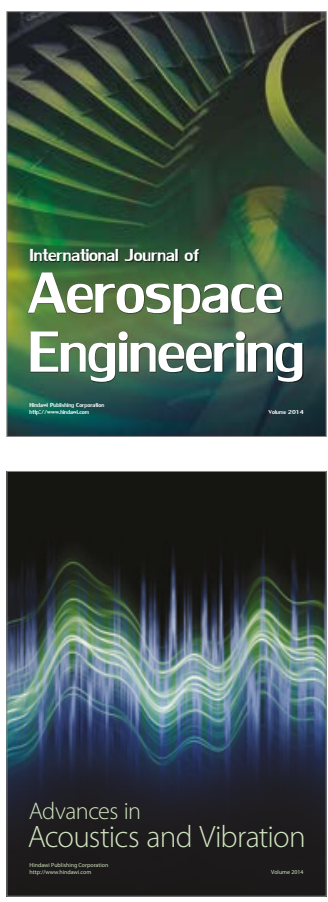

Sensor Networks 